\title{
Disability and recovery in schizophrenia: a systematic review of cognitive behavioral therapy interventions
}

\author{
Izabela Nowak ${ }^{1 *}$, Carla Sabariego ${ }^{2}$, Piotr Świtaj ${ }^{1}$ and Marta Anczewska ${ }^{1}$
}

\begin{abstract}
Background: Schizophrenia is a disabling disease that impacts all major life areas. There is a growing need for meeting the challenge of disability from a perspective that extends symptomatic reduction. Therefore, this study aimed to systematically review the extent to which traditional and "third wave" cognitive - behavioral (CBT) interventions address the whole scope of disabilities experienced by people with lived experience of schizophrenia using the WHO's International Classification of Functioning, Disability and Health (ICF) as a frame of reference. It also explores if current CBT interventions focus on recovery and what is their impact on disability domains.
\end{abstract}

Methods: Medline and PsycINFO databases were searched for studies published in English between January 2009 and December 2015. Abstracts and full papers were screened against pre-defined selection criteria by two reviewers. Methodological quality of included studies was assessed by two independent raters using the Effective Public Health Practice Project Quality assessment tool for quantitative studies (EPHPP) guidelines.

Results: A total of 50 studies were included, 35 studies evaluating traditional CBT interventions and 15 evaluating "third wave" approaches. Overall, traditional CBT interventions addressed more disability domains than "third wave" approaches and mostly focused on mental functions reflecting schizophrenia psychopathology. Seven studies met the inclusion criteria of recovery-oriented interventions. The majority of studies evaluating these interventions had however a high risk of bias, therefore evidence on their effectiveness is inconclusive.

Conclusions: Traditional CBT interventions address more disability domains than "third wave" therapies, however both approaches focus mostly on mental functions that reflect schizophrenia psychopathology. There are also few interventions that focus on recovery. These results indicate that CBT interventions going beyond symptom reduction are still needed. Recovery-focused CBT interventions seem to be a promising treatment approach as they target disability from a broader perspective including activity and participation domains. Although their effectiveness is inconclusive, they reflect users' views of recovery and trends towards improvement of mood, negative symptoms and functioning are shown.

Keywords: Schizophrenia, Disability, International Classification of Functioning, Disability and Health (ICF), Personal recovery, Cognitive-behavioral therapy

\footnotetext{
* Correspondence: inowak@ipin.edu.pl

${ }^{1}$ First Department of Psychiatry, Institute of Psychiatry and Neurology,

Sobieskiego 9, 02-957 Warsaw, Poland

Full list of author information is available at the end of the article
} 


\section{Background}

Schizophrenia is a psychotic disorder that affects about 26 million people around the world [1]. It is typically diagnosed in early adulthood, and mostly persists throughout peoples' lives [2]. Several long-term follow-up studies have challenged the view about schizophrenia poor outcome and proved that varying degrees of improvement are possible [3-5], however schizophrenia is still one of the main causes of disability worldwide [6].

The World Health Organization International Classification of Functioning, Disability and Health ICF [7] provides a unified and standard language for the description of health, functioning and disability. According to the ICF disability encompasses impairments of body functions, activity limitations or participation restrictions, arising as a result of interaction between a health condition and contextual factors (i.e. personal and environmental factors). An individual with lived experience of schizophrenia, might experience disability due to impairments of thought or perceptual functions (mental functions) as well as difficulties in family relationships and interpersonal interactions or in acquiring and keeping a job (activities and participation). Environmental factors such as accessibility to health services and appropriate treatment, systems and policies of a country, or stigmatizing societal attitudes as well as personal factors e.g. low self-esteem impact the level of disability experienced.

Results of a systematic review by Świtaj et al. [8] indeed revealed that disability in schizophrenia does not only refer to impairments of mental functions but also to several activities and participation domains. This is in line with the recently developed ICF Core Set for Schizophrenia, which in addition to the above mentioned domains also includes various environmental factors [9]. As a result, there has been a growing need on the part of clinicians and researchers to meet the challenge of reducing disability faced by people with schizophrenia from a broader perspective.

Key elements of the broader perspective are service users' views on personal recovery understood as the achievement of a valued, meaningful life, rather than clinical recovery $[10,11]$. Elements of personal recovery have been recaptured in the systematic review carried out by Leamy et al. [12] who identified them as: connectedness; hope and optimism about the future; identity; meaning in life; and empowerment (giving the acronym CHIME). Lloyd et al. [13] revealed that subjective indicators of recovery such as empowerment are associated with more objective recovery dimensions such as level of participation in the community and income from employment.

From the perspective of treatment various forms of psychosocial interventions have been recommended as an adjunct to medications, with cognitive-behavioral therapy (CBT) being one of the acknowledged interventions $[14,15]$. Cognitive behavioral therapy for psychosis
(CBTp) has gained large empirical support, however results obtained in meta-analytic reviews [16-19], have been mixed leading to a debate over the effectiveness of CBTp and pointing the need of its further development. One way of improving the outcomes of traditional CBT approaches is the inclusion of "third wave" CBT or more recently called "contextual" approaches to the theory and practice. Traditional CBT interventions actively focus on identifying and changing the thought content in specific disorders, whereas "third wave" approaches focus on modifying the context and function of thoughts [20]. A number of interventions represent "third wave" oriented CBT e.g. mindfulness-based cognitive therapy (MBCT) [21], metacognitive therapy (MCT) [22], acceptance and commitment therapy (ACT) [23], dialectical behavior therapy (DBT) [24], functional analytic psychotherapy (FAP) [25], integrative behavioral couple therapy (IBCT) [26] or person-based cognitive therapy for psychosis [27]. There is a growing evidence supporting "third wave" interventions in schizophrenia indicating moderate effect sizes in reducing negative symptoms [28].

Current systematic reviews on CBT interventions in schizophrenia mostly focus on symptomatic recovery, i.e. on mental functions, as a primary treatment target $[18,19]$. Although symptom reduction is undeniably important in schizophrenia it is less clear the extent to which traditional and "third wave" CBT interventions address the whole scope of disabilities experienced by people with lived experience of schizophrenia. Considering service users definitions of recovery it is also important to explore, whether current CBT interventions focus on recovery and what is their impact on disability domains. This information would be useful in the development of $\mathrm{CBT}$ interventions that aim to support people with lived experience of schizophrenia in overcoming disabilities experienced in daily life through a process that is in line with the personal recovery approach. The objective of this systematic review is therefore threefold:

1. to provide a comprehensive overview on disability domains considered by traditional and "third wave" CBT interventions in schizophrenia using the ICF as a frame of reference;

2. to examine whether there are CBT interventions focusing on personal recovery;

3. to examine if recovery-oriented interventions effectively impact targeted disability domains.

The review specifically answers the following questions:

a) which disability domains are being addressed by current CBT approaches?

b) are there CBT interventions that focus on recovery? 
c) what is the effectiveness of CBT interventions focusing on recovery?

\section{Methods}

We adhered to the PRISMA guidelines for conducting and reporting systematic reviews for evaluating health care interventions [29].

\section{Search strategy}

A systematic search was conducted using Medline and PsycINFO databases. Keywords, MeSH and Index terms for the search strategy were identified through reviewing systematic reviews $[16,30]$ and studies relevant to the pre-established diagnosis, intervention and study design. The full search strategy is presented in Additional file 1. The reference lists of previously published reviews were also screened in order to identify papers that might have been omitted in the systematic search.

\section{Selection criteria}

Studies were included if:

(a) published in English between January 2009 and December 2015,

(b)considered adults (18-65 years), at least $50 \%$ of the sample under the study with schizophrenia spectrum disorders diagnosed by the International Classification of Diseases, tenth edition (ICD-10) [31] or Diagnostic and Statistical Manual of Mental Disorders, fourth edition (DSM-IV) [32]. We also included studies in which schizophrenia diagnosis was confirmed on the basis of medical records or the diagnostic criteria have not been explicitly specified but the study considered people with spectrum of schizophrenia disorders.

(c) study design was Randomized Controlled Trial (RCT), Clinical Controlled Trial (CCT), observational study with/without control group,

(d)schizophrenia disability dimension was an outcome,

(e) referred to traditional or "third wave" CBT interventions.

With regards to traditional approaches we selected studies with intervention description including reference to (a) establishing links between outcomes, thoughts and beliefs, distress or problem behavior (b) included re-evaluation of perceptions, beliefs or reasoning [16] relating to the target outcomes. Regarding "third wave" interventions we included all acceptance-based, compassion-based, and mindfulness-based approaches and interventions using "third wave" strategies as one of the central components of the treatment conceptualization. In order to assess whether interventions focused on recovery, we set the following criteria: indication by authors that the intervention refers to recovery, which is further linked to personal recovery oriented intervention formulation or inclusion of personal recovery aspects in the intervention conceptualization. Personal recovery was defined according the CHIME framework [12].

Studies were excluded if:

(a) included participants with active drug or alcohol dependence, organic brain disease, severe cognitive deficits or documented mental retardation,

(b)considered primary prevention studies, phase I and II study, ecologic studies, case reports, case series, cross-sectional studies, qualitative studies, economic evaluations,

(c) the primary target of interventions was not effectiveness,

(d)CBT forming part of broader interventions,

(e) hybrid forms of existing cognitive therapy,

(f) considered unpublished studies, book chapters, dissertations, commentaries, letters to the editors, editorials, conference reports.

\section{Eligibility assessment}

Abstracts retrieved from databases were examined against the selection criteria by a trained reviewer. To increase reliability of this process $20 \%$ of randomly selected abstracts were double checked by a second reviewer, who was blind to the decision of the first researcher. Papers considered eligible were retrieved and examined by two researchers.

\section{Data extraction and data synthesis}

One reviewer extracted the following data from the included papers: the objectives of the study; study design; study population; outcome variables and questionnaires used; disability aspects; recovery orientation; and results. Extracted information about interventions involved the name, number of sessions, duration and frequency, intervention description and manual used. A matrix of traditional and "third wave" CBT interventions was provided with regards to conceptually or thematically-related categories of disability based on the ICF using the linking rules described by Cieza et al. [33]. A separate categorization of interventions focusing on recovery was also performed.

\section{Methodological assessment}

Included studies were independently assessed by two researchers using the Effective Public Health Practice Project (EPHPP) quality assessment tool [34]. This instrument permits quality evaluation of a wide range of study designs such as RCTs, CCTs, and observational studies with and without control groups. Assessed quality components included: selection bias, study design, confounders, blinding, data collection methods, withdrawals and drop-outs. Strong rating is given to a study if there is no weak component score. Moderate rating is given with 
one weak component score. Weak rating is given with two or more component rating scores.

\section{Results}

\section{Study selection}

Study selection process is presented in Fig. 1. Fifty articles were included in the review.

\section{Characteristics of included studies}

Included studies were mostly carried out in Europe $(n=31)$, predominantly in the UK $(n=21)$ and involved 3213 participants who were recruited from in-patient and out-patient settings. Forty-four papers reported participants' gender, with men being in majority (58.9\%). Mean age of participants ranged between 23.48 and 47.12 years. Only 14 studies reported participants' duration of illness, the mean ranged between 3.1 and 17.7 years. Eight studies reported the number of participants' hospitalizations, the mean ranged from 1.69 to 7.9 times. The selected studies included twenty six randomized controlled trials (RCT), eight controlled clinical trials (CCT), and sixteen cohort studies. According to the EPHPP quality assessment tool two studies $(4 \%)$ were qualified as strong, nineteen as moderate $(38 \%)$, and twenty nine $(58 \%)$ as weak. The most common reasons for the low quality of rating were missing or insufficient information regarding the selection of the study population as well as control of confounders.

Thirty-five studies considered traditional CBT interventions whereas fifteen referred to "third wave" approaches. Among these seven interventions were considered as meeting the established recovery criteria. Traditional CBT interventions were grouped according to their treatment focus, that is generic interventions $(n=15)$ or focusing on specific aspects such as hallucinations $(n=4)$, delusions $(n=3)$, negative symptoms $(n=2)$, emotions $(n=3)$, recovery $(n=5)$, suicide $(n=1)$, sleep $(n=1)$, and work $(n=1)$. Many interventions did not make a clear reference to change in beliefs, cognitive restructuring or re-evaluation of the subjective meaning of the intervention targets. Some interventions emphasized coping strategies instead [35] and others
Records excluded after abstract check due to irrelevant study population $(n=94)$, CBT not being the target intervention $(\mathrm{n}=413)$; irrelevant study design $(\mathrm{n}=1293)$ or publication type $(n=73)$, and others category $(n=623)$ which mostly considered theoretical papers. Total $(n=2496)$.

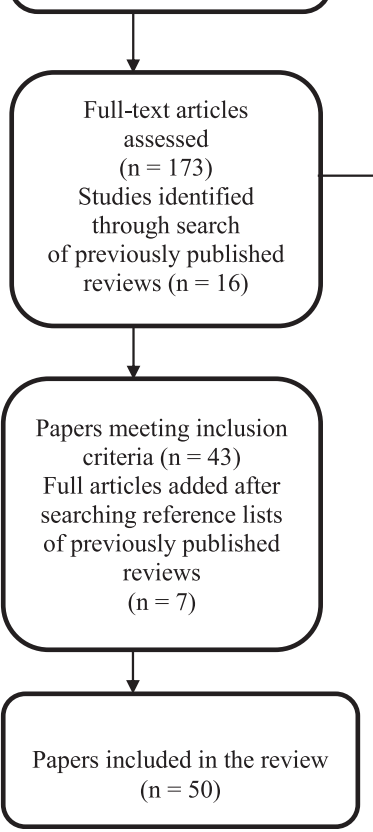

Studies excluded after full-text check due to participants not meeting the diagnostic criteria $(n=9)$, falling out of the age range $(n=14)$ and with active drug or alcohol dependence $(n=1)$; CBT not being the primary target intervention $(n=59)$; irrelevant study design or effectiveness not being the primary study target $(\mathrm{n}=34)$; outcomes not considering disability dimension $(n=8)$; studies not written in English $(n=6)$, not meeting the criteria of publication type $(n=6)$; duplicate $(n=2)$. Total $(n=139)$.

Fig. 1 Flow diagram of the study selection process 
combined CBT with other treatment approaches [36-38] but overall were described as cognitive-behavioral. The interventions were delivered on an individual, group or mixed basis, or using media-delivery modes such as a computer program, mobile SMS or internet. As regards the "third wave" interventions they were grouped into generic $(n=1)$, mindfulness-based $(n=7)$, compassion-based $(n=1)$, and acceptance-based $(n=2)$ approaches, as well as personbased cognitive therapy $(n=1)$, metacognitive therapy $(n=1)$ and recovery focused approaches $(n=2)$. Most interventions were delivered on a group basis. Some of the included "third wave" studies also used traditional CBT techniques in their treatment conceptualization $[39,40]$.

\section{Which disability domains are being addressed by current CBT approaches?}

Considering conceptualization of schizophrenia disability traditional approaches focus on changing the thought content whereas "third wave" therapies focus on modifying the context and function of thoughts. We assumed that the outcomes measuring the impact of the interventions on schizophrenia disability may also differ and the results were presented separately. Outcomes measured in traditional CBT interventions are displayed in Table 1.

Disability aspects addressed in "third wave" approaches are presented in Table 2.

It becomes evident that both traditional and "third wave" CBT approaches measured domains of mental functions, however only studies evaluating traditional CBT interventions addressed activity and participation domains. In traditional CBT approaches measured mental functions mostly referred to thought functions $(n=18)$, perceptual functions $(n=16)$, followed by emotional functions such as depressive mood $(n=14)$ and anxiety $(n=8)$. "Third wave" interventions focused more on emotional functions such as depression $(n=7)$ rather than perceptual $(n=4)$ or thought functions $(n=3)$. In the domain of activity and participation traditional CBT addressed employment $(n=4)$, relationships with others $(n=4)$ and treatment adherence $(n=2)$. There was also a number of outcomes in both traditional and "third wave" CBT interventions that we could not directly link to the ICF categories, therefore they were grouped under personal factors, global scores related to disability and others category. Results considering these categorizations also show a high number of studies measuring the impact of interventions on schizophrenia psychopathology, which was followed by global disability and global functioning scores.

\section{Are there $C B T$ interventions that focus on personal recovery?}

Seven studies were considered as focusing on personal recovery (Table 3 ).
Selected interventions varied with regards to the recovery concept. It ranged from interventions explicitly referring to the Recovery Movement [41] or recovery definitions that resemble the spirit and goals of the recovery paradigm $[42,43]$ to other concepts such as social recovery [36] or functional recovery [37]. Interventions also differed with regards to their content as many studies integrated recovery approach with a wide variety of already existing therapeutic concepts and strategies. Identifying and working towards meaningful personal goals seemed to be a core element of many recovery-focused approaches.

\section{What is the effectiveness of CBT interventions focusing on recovery?}

The impact of recovery-focused interventions on disability domains was mostly pronounced in mental functions, namely emotional functions - depression [37, 43, 44] anxiety [43], mood [42], affective flattening, and anhedonia [43]. Improvements were also reported in the domain of energy and drive functions (avolition) [41, 43], perceptual functions (hallucinations), thought functions (delusions), language functions (alogia) and interpersonal problems [43]. Global scores related to disability also showed improvements in aspects such as global psychopathology [36], general psychopathology [44], and positive symptoms [41].

Regarding the domain of activity and participation improvements were reported in work functioning at follow-up and participation in extended social network relationships across the trial [37]. Global scores of disability and functioning showed improved functioning $[37,41,42]$ as well as hours spent on economic and structured activity [36].

The above results have to be interpreted with caution as four of the studies [37, 42, 44, 45] were rated as weak with regards to the risk of bias, whereas three $[36,41,43]$ were given a moderate rating.

\section{Discussion}

In the present systematic review we provide a comprehensive overview on disability domains considered by CBT interventions in schizophrenia using the ICF as reference framework. We also examined whether there are any CBT interventions focusing on personal recovery and the impact of these interventions on disability domains. We included 35 studies evaluating traditional CBT interventions and 15 evaluating "third wave" approaches, 7 of them met our inclusion criteria of personal recovery. Traditional CBT interventions addressed more disability domains than "third wave" therapies, however in both approaches there was a strong emphasis on mental functions reflecting schizophrenia symptoms. Recovery-focused interventions differed in the degree of clarity with regards to the recovery concept. These studies show significant impact on emotional functions, negative symptoms, 
Table 1 Disability dimensions addressed by traditional CBT interventions

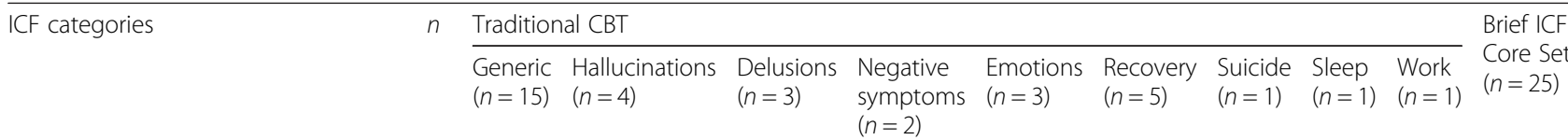

Mental functions

Global psychosocial functions (b122)

Temperament and personality

unctions (b126)

Worry (b1263)

Energy and drive (b130)

Apathy (b130)

Sleep functions (b134)

Attention (b140)

Psychomotor function (b147)

Emotional functions (b152)

Depression (b1522)

Anxiety (b152)

Anhedonia (b1520)

Hostility (b1522)

Flat affect (b1522)

In general (b152)

Anger (b152)

Perceptual function (b156)

Thought functions (b160)

Suicidal ideation (b1602)

Higher-level cognitive functions (b164)

Cognitive flexibility (b1643)

Insight (b1644)

Alogia (b167)

Experience of self and time

functions (b180)

Acquiring skills (d155)

$3 x$
$\mathrm{X}$

$x$

\begin{tabular}{|c|c|c|c|c|c|c|c|}
\hline 14 & $x$ & & $x$ & & $x$ & $x$ & \\
\hline 8 & $x$ & $x$ & & & $x$ & $x$ & \\
\hline 4 & $x$ & & $x$ & & $x$ & & \\
\hline 2 & $x$ & & & & & $x$ & \\
\hline 4 & $x$ & & $x$ & & $x$ & & \\
\hline 4 & $x$ & $x$ & & & $x$ & & \\
\hline 1 & & & & $x$ & & & \\
\hline 16 & $x$ & & & $x$ & $x$ & $x$ & $x$ \\
\hline 18 & $x$ & $x$ & & $x$ & $x$ & $x$ & $x$ \\
\hline 3 & $x$ & & & & & $x$ & \\
\hline 2 & $x$ & $x$ & & & & & \\
\hline 2 & $x$ & $x$ & & & & & \\
\hline 7 & $x$ & & & & $x$ & & \\
\hline 4 & $x$ & & $x$ & & $x$ & & \\
\hline
\end{tabular}

Basic interpersonal interactions (d710)

Complex interpersonal

interactions (d720)

Aggressive behaviour (d7202)

Family relationships (d760)

Employment in general (d850) 
Table 1 Disability dimensions addressed by traditional CBT interventions (Continued)

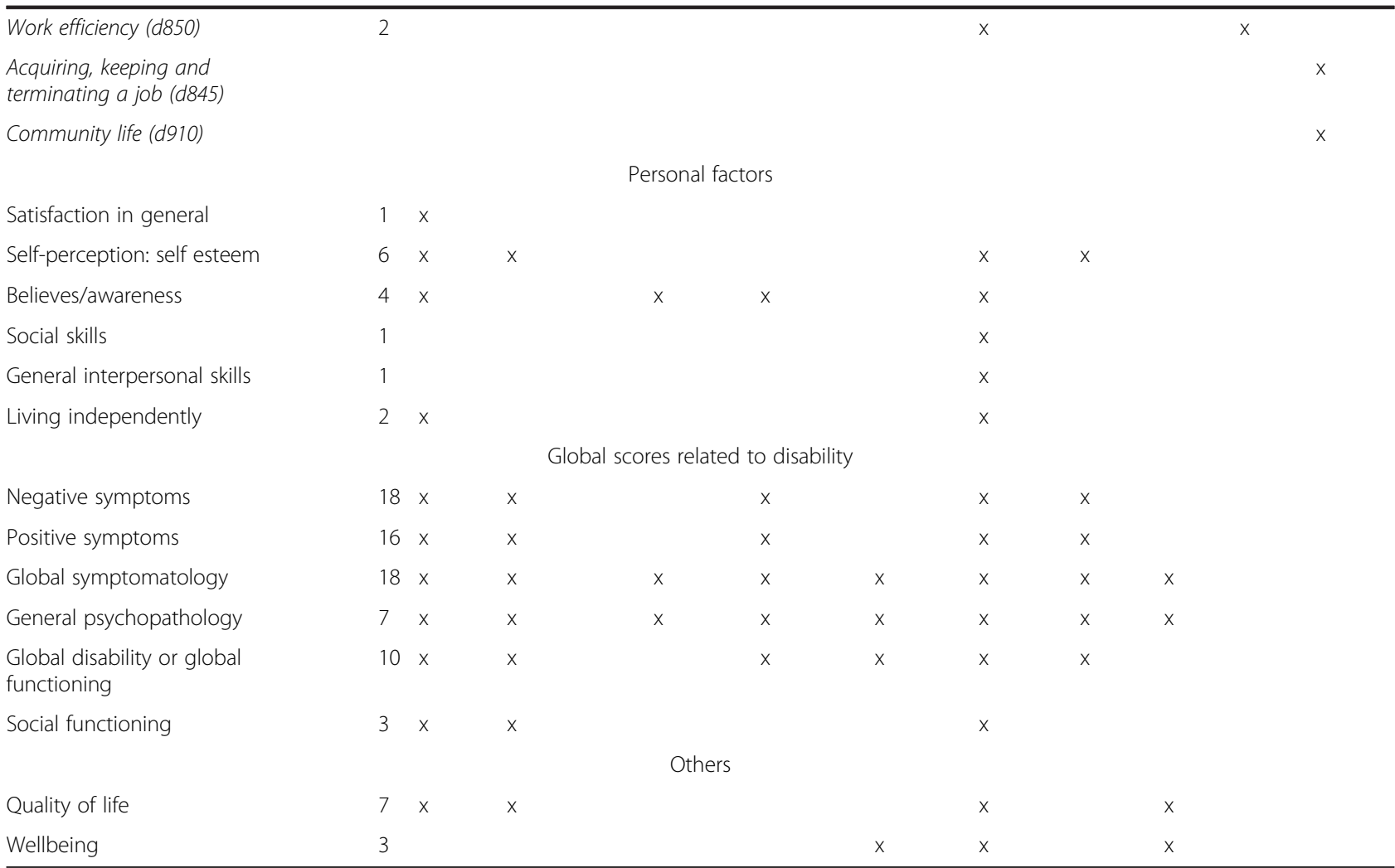

$n$ the number of articles addressing the disability dimension, $x$ considered disability dimension

schizophrenia psychopathology, work functioning, participation in extended social network relationships, global disability, functioning and hours spent on economic and structured activities. However, only three recovery-focused studies were rated as fair regarding the risk of bias.

All studies included in this review have a strong focus on mental functions, especially perceptual functions, thought functions and depressive mood, and fail to measure the impact of their interventions on a broad range of activity and participation domains. However, in a recently published systematic review on psychosocial difficulties in schizophrenia [8] the proportion of reported mental functions against the activity and participation domain is comparable. Results refereeing to mental functions are in line with those reported by Świtaj et al. [8] where the most extensively studied were cognitive $(27 \%)$ and emotional functions $(27 \%)$. This resembles the core aim of many CBT interventions, i.e. targeting the distress resulting from psychotic symptoms. As reported by Jones et al. [16] outcomes in CBT for psychosis are often defined in terms of the reduction in hallucinatory and delusional experience instead of eliciting emotional and behavioral changes, however our findings also indicate the strong emphasis on outcomes related to depressive mood. This supports the stance on commonality of affective disorders in psychosis and its contribution to the suffering caused by the illness and exacerbation of deficits in psychosocial functioning often preceding attempted and completed suicide $[46,47]$.

With regards to activity and participation the impact of traditional CBT interventions mostly revolved around the area of relationships with others and employment which is also in line with Switaj et al. [8] results. In studies evaluating "third wave" CBT no activity and participation domain was included as an outcome but studies reported on global scores related to disability, functioning and social functioning. In terms of treatment conceptualization "third wave" approaches differ from the traditional CBT interventions by deemphasizing the importance of changing the content and frequency of cognition while focusing on mindfulness and acceptance processes [48]. However as indicated by Khoury et al. [28] targeting these processes among people diagnosed with schizophrenia spectrum disorders later translates into improvement of symptoms, functioning and quality of life. This might explain why the area of activity and participation was not the target of "third wave" approaches.

Our results indicate a mismatch between what is targeted in CBT for schizophrenia and the scope of disabilities experienced by persons with schizophrenia in daily life. In a recent qualitative study it was shown that users' perception of psychosocial difficulties or disability domains, revolve 
Table 2 Disability dimensions addressed by "third wave" CBT

\begin{tabular}{|c|c|c|c|c|c|c|c|c|c|}
\hline \multirow[t]{2}{*}{ ICF codes } & \multirow[t]{2}{*}{$n$} & \multicolumn{7}{|c|}{ Third wave CBT } & \multirow{2}{*}{$\begin{array}{l}\text { Brief ICF } \\
\text { Core Se } \\
(n=25)\end{array}$} \\
\hline & & $\begin{array}{l}\text { Generic } \\
(n=1)\end{array}$ & $\begin{array}{l}\text { Mindfulness } \\
\text { based } \\
(n=7)\end{array}$ & $\begin{array}{l}\text { Compassion } \\
\text { based } \\
(n=1)\end{array}$ & $\begin{array}{l}\text { Acceptance } \\
\text { based } \\
(n=2)\end{array}$ & $\begin{array}{l}\text { Person-based } \\
\text { cognitive therapy } \\
(n=1)\end{array}$ & $\begin{array}{l}\text { Metacognitive } \\
\text { therapy } \\
(n=1)\end{array}$ & $\begin{array}{l}\text { Recovery } \\
(n=2)\end{array}$ & \\
\hline
\end{tabular}

Mental functions

Global psychosocial functions (b122)

Temperament and personality

functions (b126)

Mood (b1263)

Optimism (b1265)

Energy and drive functions (b130)

Attention functions (b140)

Emotional functions (b152)

Depression (b1522)

Anxiety (b152)

Anhedonia (b1520)

Hostility (b1522)

In general

Mania (b152)

Emotional regulation (b1521)

Perceptual function (b156)

Thought functions (b160)

Higher-level cognitive functions (b164)

Insight (b1644)

Sleep functions (b134)

In general (b134)

Experience of self and time functions (b180)

Acquiring skills (d155)

Solving problems (d175)

Carrying out daily routine (d230)

Handling stress and other psychological demands (d240)

Looking after one's health (d570)

Basic interpersonal interactions (d710)

Complex interpersonal interactions (d720)

Family relationships (d760)

Acquiring, keeping and terminating

a job (d845)

Community life (d910)

Activities and participation

Perception and experience of

Personal factors

social support

Satisfaction in general

Self-perception (in general) 
Table 2 Disability dimensions addressed by "third wave" CBT (Continued)

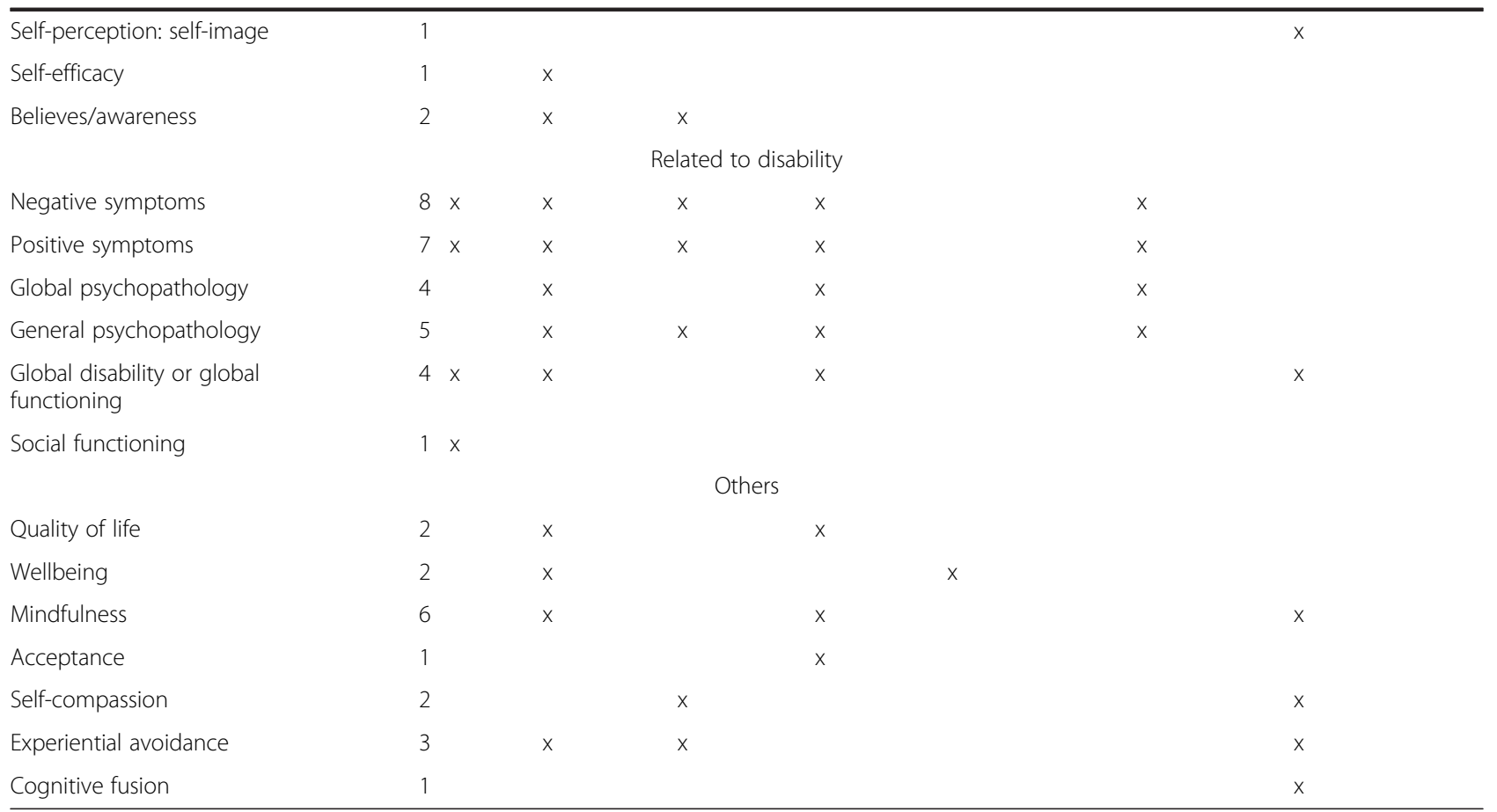

$n$ the number of articles addressing the disability dimension, $x$ considered disability dimension

around the activity and participation areas such problems in relationships or finding and keeping work and place to live. Many of the indicated psychosocial difficulties also considered personal factors such as problems with selfesteem or environmental factors e.g. experience of stigma or frustrations with mental health services. Interestingly users' views of the domain of mental functions refer to emotional functions for example feeling fear or despair but not to impairments of thought or perceptual functions [49]. This may indicate that when human experience is considered these areas of functioning seem to be less prominent.

Several reasons might explain the strong focus on mental functions. The focus of traditional CBT interventions is mostly on symptoms alleviation rather than functioning, whether by directly targeting the psychotic symptoms or distress related with them. The underlying hypothesis behind that is the assumption that symptom alleviation will automatically translate in improvement in functioning in general, what might explain why measures of global disability, functioning or social functioning are included while specific functioning domains related to activity and participation are missing. However, as shown by Wykes et al. [17] improvements in positive symptoms were correlated with improvements in negative symptoms but did not quite reach significance with regards to improved global functioning among people with schizophrenia spectrum disorders. Instead improvements in negative symptoms were indeed significantly correlated with better functioning and improved mood. The majority of traditional CBT interventions included in this review targeted a wide spectrum of symptoms including negative symptoms and mood while "third wave" interventions targeted emotional distress arising from psychotic symptoms. Having in mind the recent works shading light on the activity and participation outcomes important for persons with schizophrenia, it would be highly relevant if studies would indeed examine the effectiveness of their interventions in these areas.

Although expectations of people with lived experience of schizophrenia revolve around the recovery paradigm, we have identified few CBT interventions focusing on personal recovery. Studies included in our review reflect the diversity of existing recovery definitions. They also varied in their scope, however identifying and working towards meaningful personal goals seemed to be a core element of many recovery-focused approaches. With regards to the targeted disability dimensions the included recovery interventions addressed relatively wide scope of both mental functions and activity and participation domains. Interestingly they did not extensively focused on perceptual or thought functions but targeted disability aspects that mostly revolve around negative symptoms and emotional functions. In the area of activity and participation they targeted relationships, and employment. This points out that these interventions come closer to the desired broad perspective than traditional CBT interventions due to targeting personal recovery process but also using objectives measures of 
Table 3 Characteristics of recovery focused interventions

\begin{tabular}{|c|c|c|c|c|c|c|c|c|c|}
\hline $\begin{array}{l}\text { Study } \\
\text { (country) }\end{array}$ & Recovery & Study design & $\mathrm{n}$ & Intervention group & $\begin{array}{l}\text { Control } \\
\text { group }\end{array}$ & Follow up & Outcome measures & Impact on disability & $\begin{array}{l}\text { Quality of } \\
\text { rating }\end{array}$ \\
\hline $\begin{array}{l}\text { Farhall et al., } \\
2009 \text { Australia }\end{array}$ & $\begin{array}{l}\text { Recovery concept: recovery. } \\
\text { Main content: the recovery } \\
\text { therapy intervention is a form } \\
\text { of CBTp, which focuses on } \\
\text { agreed recovery goals using } \\
\text { one or more recovery } \\
\text { therapy components such as } \\
\text { everyday coping, working } \\
\text { with symptoms, } \\
\text { understanding experience of } \\
\text { psychosis, strengthening } \\
\text { adaptive view of self, } \\
\text { personal/emotional issues or } \\
\text { comorbid disorders, relapse } \\
\text { prevention, and family or } \\
\text { social reintegration. }\end{array}$ & RCT & $\begin{array}{l}94 \text { total } \\
45 \text { intervention } \\
49 \text { control }\end{array}$ & $\begin{array}{l}\text { Recovery therapy } \\
\text { (CBTp) + TAU } \\
\text { Individual } \\
12-24 \text { sessions }\end{array}$ & TAU & 9 months & $\begin{array}{l}\text { Primary measures: } \\
\text { PANSS; HADS. } \\
\text { Secondary measures: } \\
\text { RSE; Self Report } \\
\text { Insight Scale; LSP. }\end{array}$ & $\begin{array}{l}\text { No statistically significant } \\
\text { differences between } \\
\text { CBTp + TAU and TAU. }\end{array}$ & Weak \\
\hline $\begin{array}{l}\text { Fowler et al., } \\
2009 \text { The UK }\end{array}$ & $\begin{array}{l}\text { Recovery concept: social } \\
\text { recovery. } \\
\text { Main content: stage one } \\
\text { involved formulation of the } \\
\text { person in social recovery as } \\
\text { well as identifying day-to-day } \\
\text { meaningful personal goals to } \\
\text { address motivation and } \\
\text { hopelessness. Stage two } \\
\text { involved identifying and } \\
\text { working towards medium- } \\
\text { to long-term goals and } \\
\text { promotion of a sense of } \\
\text { agency and addressing } \\
\text { hopelessness, feelings of } \\
\text { stigma and negative beliefs } \\
\text { about self and others. Stage } \\
\text { three involved the active } \\
\text { promotion of social activity, } \\
\text { work, education and leisure } \\
\text { linked to meaningful goals, } \\
\text { while managing symptoms } \\
\text { of anxiety and low-level } \\
\text { psychotic symptoms. }\end{array}$ & $C C T^{*}$ & $\begin{array}{l}77 \text { total } \\
35 \text { intervention } \\
42 \text { control }\end{array}$ & $\begin{array}{l}\text { Social Recovery } \\
\text { Cognitive Behaviour } \\
\text { Therapy (SRCBT) + } \\
\text { TAU } \\
\text { Mean of } 12 \text { sessions }\end{array}$ & TAU & $\begin{array}{l}\text { No follow } \\
\text { up }\end{array}$ & $\begin{array}{l}\text { Primary measures: } \\
\text { Time Use Survey } \\
\text { Secondary measures: } \\
\text { PANSS; BHS; QLS; } \\
\text { Tertiary assessments: } \\
\text { BDI-II; BAI; SOFAS; } \\
\text { CAN. }\end{array}$ & $\begin{array}{l}\text { No main effects of CBT } \\
\text { treatment for any of the } \\
\text { outcome variables for the } \\
\text { total sample. } \\
\text { Global scores: } \\
\text { Non-affective psychosis } \\
\text { group improved on } \\
\text { PANSS. } \\
\text { Non-affective psychosis } \\
\text { group improved on } \\
\text { constructive economic } \\
\text { activity and structured } \\
\text { activity (Time Use Survey). }\end{array}$ & Moderate \\
\hline $\begin{array}{l}\text { Grant et al., } \\
2012 \\
\text { The USA }\end{array}$ & $\begin{array}{l}\text { Recovery concept: the } \\
\text { Recovery Movement with } \\
\text { central features referring to } \\
\text { goal-directed framework, } \\
\text { personalized and person- } \\
\text { oriented therapeutic } \\
\text { approach highlighting the }\end{array}$ & $\mathrm{RCT}$ & $\begin{array}{l}60 \text { total } \\
31 \text { intervention } \\
29 \text { control }\end{array}$ & $\begin{array}{l}\text { Cognitive Therapy } \\
\text { plus standard } \\
\text { treatment (ST) } \\
\text { Flexible }\end{array}$ & $\begin{array}{l}\text { Standard } \\
\text { treatment } \\
\text { (ST) }\end{array}$ & $\begin{array}{l}6 \text { months; } \\
12 \text { months; } \\
18 \text { months. }\end{array}$ & $\begin{array}{l}\text { Primary measures: } \\
\text { GAS. } \\
\text { Secondary measures: } \\
\text { SANS, SAPS. }\end{array}$ & $\begin{array}{l}\text { Mental functions: } \\
\text { Avolition-apathy (SANS) } \\
\text { across the trial } \\
\text { Global scores: } \\
\text { Positive symptoms (SAPS) } \\
\text { across the trial. } \\
\text { Global functioning (GAS) } \\
\text { across the trial. }\end{array}$ & Moderate \\
\hline
\end{tabular}


Table 3 Characteristics of recovery focused interventions (Continued)

\begin{tabular}{|c|c|c|c|c|c|c|c|c|c|}
\hline & $\begin{array}{l}\text { patients' interests, assets, and } \\
\text { strengths. } \\
\text { Main content: initial sessions } \\
\text { focused on enhancing the } \\
\text { therapeutic relationship and } \\
\text { stimulating patients' interest } \\
\text { and motivation to focus } \\
\text { respectively on achievable } \\
\text { goals. Impediments to goals } \\
\text { achievement were also } \\
\text { addressed in the later phases } \\
\text { of the intervention. }\end{array}$ & & & & & & & & \\
\hline $\begin{array}{l}\text { Johns et al., } \\
2015 \\
\text { The UK }\end{array}$ & $\begin{array}{l}\text { Recovery concept: recovery } \\
\text { referred to as "living a } \\
\text { satisfying, hopeful and } \\
\text { contributing life even with } \\
\text { limitations caused by the } \\
\text { illness" and "having a sense } \\
\text { of purpose and direction". } \\
\text { Main content: the authors } \\
\text { described the interventions } \\
\text { as compatible with } \\
\text { conceptualizations of } \\
\text { recovery. The intervention } \\
\text { promoted psychological } \\
\text { flexibility (a more accepting, } \\
\text { mindful, and de-fused } \\
\text { approach) in response to } \\
\text { symptoms of psychosis and } \\
\text { associated emotions/ } \\
\text { thoughts, in order to help } \\
\text { the person act in accordance } \\
\text { with their personal values. }\end{array}$ & Pre + post & 89 total & $\begin{array}{l}\text { Acceptance and } \\
\text { Commitment Therapy } \\
\text { Group } \\
4 \text { sessions, } \\
\text { one optional } \\
\text { telephone session }\end{array}$ & $\begin{array}{l}\text { No control } \\
\text { group }\end{array}$ & 20 weeks & $\begin{array}{l}\text { The Sheehan } \\
\text { Disability Scales, } \\
\text { HADS, AAQ-II, CFQ, } \\
\text { SMQ. }\end{array}$ & $\begin{array}{l}\text { Mental functions: } \\
\text { Mood over time (HADS) } \\
\text { Global scores: } \\
\text { Functioning over time } \\
\text { (The Sheehan Disability } \\
\text { Scales) } \\
\text { Other: } \\
\text { Processes targeted by the } \\
\text { intervention (AAQ-II, CFQ, } \\
\text { SMQ). }\end{array}$ & Weak \\
\hline $\begin{array}{l}\text { Laithwaite } \\
\text { et al., } 2009 \\
\text { The UK }\end{array}$ & $\begin{array}{l}\text { Recovery concept: recovery. } \\
\text { Main content: a recovery } \\
\text { intervention was based on } \\
\text { the compassionate mind } \\
\text { training. During the first } \\
\text { module of the intervention } \\
\text { participants were encouraged } \\
\text { to think about their recovery } \\
\text { beyond symptom reduction } \\
\text { and as a journey of } \\
\text { experience. Further modules } \\
\text { targeted compassion with } \\
\text { reference to working on } \\
\text { strength, acceptance, } \\
\text { forgiveness as well as } \\
\text { developing the ideal friend. } \\
\text { The last module focused on }\end{array}$ & Pre + post & 19 total & $\begin{array}{l}\text { Compassionate mind } \\
\text { training (CMT) } \\
\text { Group } \\
20 \text { sessions }\end{array}$ & $\begin{array}{l}\text { No control } \\
\text { group }\end{array}$ & 6 weeks & $\begin{array}{l}\text { Primary measures: } \\
\text { SCS, OAS, SeCS, BDI-II, } \\
\text { RSE, SIP-AD. Second- } \\
\text { ary measures: PANSS. }\end{array}$ & $\begin{array}{l}\text { Mental functions: } \\
\text { Depression (BDI-II) } \\
\text { Global scores: } \\
\text { General psychopathology } \\
\text { (PANSS) } \\
\text { Personal factors: } \\
\text { Comparisons to others } \\
\text { (SCS), self-esteem (RSE), } \\
\text { external shame (OAS). }\end{array}$ & Weak \\
\hline
\end{tabular}

Scales)

Processes targeted by the intervention (AAQ-II, CFQ

$\mathrm{SMQ}$ ). 
Table 3 Characteristics of recovery focused interventions (Continued)

\begin{tabular}{|c|c|c|c|c|c|c|c|c|c|}
\hline & $\begin{array}{l}\text { developing plans for recovery } \\
\text { after psychosis. }\end{array}$ & & & & & & & & \\
\hline $\begin{array}{l}\text { Study } \\
\text { (country) }\end{array}$ & Recovery & Study design & $\mathrm{n}$ & Intervention group & $\begin{array}{l}\text { Control } \\
\text { group }\end{array}$ & Follow up & Outcome measures & Impact on disability & $\begin{array}{l}\text { Quality of } \\
\text { rating }\end{array}$ \\
\hline $\begin{array}{l}\text { Penn et al., } \\
2011 \\
\text { The USA }\end{array}$ & $\begin{array}{l}\text { Recovery concept: illness } \\
\text { management and functional } \\
\text { recovery. } \\
\text { Main content: the program } \\
\text { placed an emphasis on } \\
\text { personal goal pursuit to } \\
\text { foster optimism and self- } \\
\text { esteem, targeted malleable } \\
\text { factors that may enhance } \\
\text { recovery such as residual } \\
\text { symptoms and substance } \\
\text { use, and enlists external } \\
\text { social support to maximize } \\
\text { therapeutic gains and } \\
\text { engagement. The intervention } \\
\text { consisted of four phases: } \\
\text { engagement and wellness } \\
\text { management; substance use; } \\
\text { persistent symptoms; and } \\
\text { functional recovery. }\end{array}$ & $\mathrm{RCT}$ & $\begin{array}{l}46 \text { total } \\
23 \text { intervention } \\
23 \text { control }\end{array}$ & $\begin{array}{l}\text { Graduated Recovery } \\
\text { Intervention Program } \\
\text { (GRIP) (CBT) + TAU } \\
\text { Individual } \\
36 \text { sessions }\end{array}$ & TAU & 3 months & $\begin{array}{l}\text { Primary outcomes: } \\
\text { QLS; RFS, MCAS; SSPA. } \\
\text { Secondary outcomes: } \\
\text { the PANSS; CDSS; } \\
\text { subscales from the } \\
\text { Scales of } \\
\text { Psychological Well- } \\
\text { Being; MSPSS; AUS; } \\
\text { DUS; BEMIB. }\end{array}$ & $\begin{array}{l}\text { Activity and participation } \\
\text { domain: Work functioning } \\
\text { at follow-up (RFS) } \\
\text { Within-group analysis } \\
\text { Mental functions: } \\
\text { Depression (CDSS) across } \\
\text { the trial } \\
\text { Activity and participation } \\
\text { domain: } \\
\text { Extended social network } \\
\text { (RFS) across the trial } \\
\text { Global scores: } \\
\text { Total role functioning } \\
\text { (RFS) across the trial } \\
\text { Personal factors: } \\
\text { Social competence } \\
\text { (MCAS) across the trial }\end{array}$ & Weak \\
\hline $\begin{array}{l}\text { Williams et al., } \\
2014 \\
\text { The UK }\end{array}$ & $\begin{array}{l}\text { Recovery concept: the } \\
\text { recovery model described as } \\
\text { building a meaningful and } \\
\text { satisfying life defined by the } \\
\text { person themselves, focusing } \\
\text { upon strengths and wellness } \\
\text { not illness and pathology, a } \\
\text { sense of hope, and possibility } \\
\text { of change, promotion of self- } \\
\text { management and personal } \\
\text { identity (not patient identity), } \\
\text { the therapeutic relationship } \\
\text { being one of partnership } \\
\text { not "expert-patient"; and } \\
\text { encouragement of group } \\
\text { members to help each other } \\
\text { in recovery. } \\
\text { Main content: The } \\
\text { intervention was delivered in } \\
\text { five modules. The first one } \\
\text { focused on engagement and } \\
\text { treatment preparation, } \\
\text { module two on individual } \\
\text { analysis of the person and } \\
\text { schizophrenia, module three } \\
\text { understanding and managing }\end{array}$ & CCT & $\begin{array}{l}47 \text { total } \\
30 \text { intervention } \\
17 \text { control }\end{array}$ & $\begin{array}{l}\text { Cognitive-behavioural } \\
\text { therapy } \\
\text { Individual and group } \\
35 \text { planned sessions }\end{array}$ & TAU & $\begin{array}{l}\text { No follow } \\
\text { up }\end{array}$ & $\begin{array}{l}\text { SAPS, SANS, PSYRATS, } \\
\text { DASS, IIP. }\end{array}$ & $\begin{array}{l}\text { Mental functions: } \\
\text { Delusions (SAPS) } \\
\text { Hallucinations (SAPS) } \\
\text { Affective flattening (SANS) } \\
\text { Alogia (SANS) } \\
\text { Anhedonia (SANS) } \\
\text { Avolition (SANS) } \\
\text { Depression (DASS) } \\
\text { Anxiety (DASS) } \\
\text { Overall interpersonal } \\
\text { problems (social } \\
\text { inhibition and self- } \\
\text { sacrifice) (IIP) }\end{array}$ & Moderate \\
\hline
\end{tabular}

use, and enlists external

ocial support to maximize

engagement. The intervention

consisted of four phases:

management; substance use

persistent symptoms; and

Recovery concept: the

47 tot

No follow

SAPS, SA

the defined by the

person themselves, focusing

not illness and pathology, a

sense of hope, and possibility

of change, promotion of self-

identity (not patient identity)

being one of partnership

members to help each other

in recovery.

intervention was delivered in

five modules. The first one

Individual and group

Alogia (SANS)

nhedonia (SANS)

Depression (DASS)

Anxiety (DASS)

nhibition and self-

ing and managin 
Table 3 Characteristics of recovery focused interventions (Continued)

$$
\begin{aligned}
& \text { positive symptoms, module } \\
& \text { four maximizing mental } \\
& \text { health and module five } \\
& \text { reviews of personal aims and } \\
& \text { goals, reinforcement of } \\
& \text { protective factors, } \\
& \text { development of a detailed } \\
& \text { relapse recognition and } \\
& \text { staying well plan as well as } \\
& \text { discussion of future } \\
& \text { directions. }
\end{aligned}
$$

CCT Clinical Controlled Trial, CCT* Clinical Controlled Trial (EPHPP criteria regarding RCTs where the allocation method is not described or allocation is transparent before assignment), Pre + post Cohort (one group pre + post (before and after)), RCT Randomized Controlled Trial, TAU Treatment as usual, $n$ number of participants, PANSS Positive and Negative Syndrome scale, HADS The Hospital Anxiety and Depression Scale, RSE Rosenberg SelfEsteem scale, LSP the Life Skills Profile, BHS Beck Hopelessness Scale, QLS Quality of Life Scale, BDI-Il the Beck Depression Inventory, BAl the Beck Anxiety Inventory, SOFAS the Social and Occupational Functioning Assessment Scale, CAN the Camberwell Assessment of Needs, GAS The Global Assessment Scale, SANS Scale for the Assessment of Negative Symptoms, SAPS The Scale for the Assessment of Positive Symptoms, AAQ-II The Acceptance and Action Questionnaire, CFQ The Cognitive Fusion Questionnaire, SMQ The Southampton Mindfulness Questionnaire, SCS Social Comparison Scale, OAS The Other as Shamer Scale, SeCS Self-Compassion Scale, SIP-AD The SelfImage Profile for Adults, RFS The Role Functioning Scale, MCAS The Multnomah Community Ability Scale, SSPA The Social Skills Performance Assessment, CDSS the Calgary Depression Scale for Schizophrenia, MSPSS The Multidimensional Scale of Perceived Social Support, AUS the Alcohol Use Scale, DUS Drug Use Scale, BEMIB The Brief Evaluation of Medication Influence and Beliefs, PSYRATS the Psychotic Symptom Rating Scales, DASS Depression Anxiety Stress Scale, IIP The Inventory of Interpersonal Problems 
negative symptoms which were shown to be related with increased functioning and mood.

The evidence on effectiveness of these interventions is inconclusive, due to the fact that many addressed outcomes considered global scores of disability and functioning and that four of the seven included studies had weak rating regarding study quality. Studies of good methodological quality including as outcomes not global functioning but the specific functioning domains relevant to persons with schizophrenia are therefore needed.

This review should be interpreted considering several limitations. Firstly, we only analyzed papers that were published in English and used two databases. Nevertheless, to complement the search we checked reference lists of other systematic reviews. Secondly, we set the time limit 20092015 for the selected studies, therefore it is possible we did not consider some relevant papers that were published before this time frame. Thirdly, we cannot generalize the findings as majority of studies came from high income countries and disabilities in schizophrenia may depend on the economic, political and cultural context [8]. Fourthly, despite the existence of guidelines for developing recoveryoriented services we felt that the implications for clinical practice were not clear $[50,51]$. Therefore, we used the CHIME personal recovery framework as it provides useful information regarding the key recovery process to be potentially targeted by the interventions [12, 52]. Another limitation of the study is that integrative metacognitive models [53, 54], which have been specifically designed to target subjective recovery were not considered in our review. Further studies should evaluate the impact of such interventions on schizophrenia disability.

\section{Conclusions}

Despite the growing need of shifting the focus from symptom-oriented approaches to treatment conceptualizations that support real-world functioning of service users, our study indicate that traditional and "third wave" CBT interventions mostly focus on aspects of disability that relate to mental functions. There are also few interventions that focus on personal recovery, however they seem to be a promising treatment approach as they target disability from a broader perspective including activity and participation domains. Despite the limited evidence of their effectiveness it might be valuable to explore further possibilities of developing recovery-oriented CBT interventions as they reflect users' views of recovery and target disability outcomes that in previous studies have been shown to improve mood and functioning. Perhaps the best practices from both traditional and "third wave" approaches could be combined in order to maximize their therapeutic potential in terms of what matters to persons with schizophrenia.

\section{Additional file}

Additional file 1: Search strategies for MEDLINE and PsycINFO. (DOCX 14 kb)

\section{Abbreviations}

$A C T$, acceptance and commitment therapy; CBT, cognitive - behavioral interventions/therapy; CBTp, cognitive-behavioral therapy for psychosis; CCT, Clinical Controlled Trial; CHIME, connectedness, hope and optimism about the future, identity, meaning in life, empowerment; DBT, dialectical behavior therapy; DSM-IV, American Psychiatric Association Diagnostic and Statistical Manual of Mental Disorders, fourth edition; EPHPP, Effective Public Health Practice Project Quality assessment tool for quantitative studies; FAP, functional analytic psychotherapy; IBCT, integrative couple therapy; ICD-10, the International Classification of Diseases, tenth edition; ICF, International Classification of Functioning, Disability and Health; MBCT, mindfulness-based cognitive therapy; MCT, metacognitive therapy; RCT, Randomized Controlled Trial

\section{Acknowledgements}

We wish to thank the reviewers for their insightful comments on earlier versions of this manuscript.

\section{Funding}

The research leading to these results has received funding from the People Programme (Marie Curie Actions) of the European Union's Seventh Framework Programme FP7/2007 - 2013 under REA grant agreement $n^{\circ} 316795$.

\section{Availability of data and materials}

The data and materials used in this review are available on request.

\section{Authors' contributions}

IN carried out the search of literature, reviewed the abstracts and full texts, evaluated the study quality, and drafted the manuscript. PŚ reviewed the abstracts, full texts as well as assessed independently the quality of studies as a second reviewer. CS and MA made important contributions to the study design and data interpretation. The final manuscript was critically revised and approved by all authors.

\section{Competing interests}

The authors declare that they have no competing interests.

\section{Consent for publication}

Not applicable.

Ethics approval and consent to participate

Not applicable.

\section{Author details}

${ }^{1}$ First Department of Psychiatry, Institute of Psychiatry and Neurology, Sobieskiego 9, 02-957 Warsaw, Poland. 'Department of Medical Informatics, Biometry and Epidemiology - IBE, Chair for Public Health and Health Services Research, Research Unit for Biopsychosocial Health,

Ludwig-Maximilians-Universität München, Munich, Germany.

Received: 31 July 2015 Accepted: 7 June 2016

Published online: 11 July 2016

\section{References}

1. World Health Organization. The global burden of disease: 2004 update. 2008. http://www.who.int/healthinfo/global_burden_disease/2004_report_ update/en/. Accessed 25 July 2015.

2. Tandon R, Nasrallah HA, Keshavan MS. Schizophrenia, "just the facts" 4. Clinical features and conceptualization. Schizophr Res. 2009;110:1-23.

3. Bleuler M. The Schizophrenia Disorders. Long-Term Patient and Family Studies. New Haven and London: Yale University Press; 1978.

4. Harding CM, Brooks GW, Ashikaga T, Strauss JS, Breier A. The Vermont longitudinal study of persons with severe mental illness. I. Methodology, study samples, and overall status 32 years later. Am J Psychiatry. 1987; 144:718-26.

5. Jobe TH, Harrow M. Long-term outcome of patients with schizophrenia: a review. Can J Psychiatry. 2005;50:892-900. 
6. World Health Organization. World report on disability 2011. http://www. who.int/disabilities/world_report/2011/report.pdf. Accessed 25 July 2015.

7. World Health Organization. International Classification of Functioning, Disability and Health-ICF. Geneva: World Health Organization; 2001.

8. Świtaj P, Anczewska M, Chrostek A, Sabariego C, Cieza A, Bickenbach J, et al. Disability and schizophrenia: a systematic review of experienced psychosocial difficulties. BMC Psychiatry. 2012;12:193.

9. Brief ICF Core Set for Schizophrenia. http://www.icf-research-branch.org/ download/send/9-mentalhealth/255-brief-icf-core-set-for-schizophrenia. Accessed 26 July 2015.

10. Deegan PE. Recovery: the lived experience of rehabilitation. Psychosoc Rehabil J. 1988;11:11-9.

11. Andresen R, Oades L, Caputi P. Psychological recovery: beyond mental illness. Chichester, West Sussex: Wiley-Blackwell; 2011.

12. Leamy M, Bird V, Le Boutillier C, Williams J, Slade M. Conceptual framework for personal recovery in mental health: systematic review and narrative synthesis. Br J Psychiatry. 2011;199:445-52.

13. Lloyd C, King R, Moore L. Subjective and objective indicators of recovery in severe mental illness: a cross-sectional study. Int J Soc Psychiatry. 2010;56: 220-9.

14. Dixon LB, Dickerson F, Bellack AS, Bennett M, Dickinson D, Goldberg RW et al. The 2009 schizophrenia PORT psychosocial treatment recommendations and summary statements. Schizophr Bull. 2010;36:48-70.

15. National Collaborating Centre for Mental Health. Psychosis and schizophrenia in adults. National Clinical Guideline Number 178. London: National Institute for Health and Clinical Excellence; 2014.

16. Jones C, Hacker D, Cormac I, Meaden A, Irving CB. Cognitive behaviour therapy versus other psychosocial treatments for schizophrenia. Cochrane Database of Systematic Reviews 2012, Issue 4. Art No.: CD008712. doi:10. 1002/14651858.CD008712.pub2.

17. Wykes T, Steel C, Everitt B, Tarrier N. Cognitive behavior therapy for schizophrenia: effect sizes, clinical models, and methodological rigor. Schizophr Bull. 2008;34:523-37.

18. Jauhar S, McKenna PJ, Radua J, Fung E, Salvador R, Laws KR. Cognitivebehavioural therapy for the symptoms of schizophrenia: systematic review and meta-analysis with examination of potential bias. Br J Psychiatry. 2014;204:20-9.

19. van der Gaag M, Valmaggia LR, Smit F. The effects of individually tailored formulation-based cognitive behavioural therapy in auditory hallucinations and delusions: a meta-analysis. Schizophr Res. 2014;156:30-7.

20. Hayes SC, Villatte M, Levin M, Hildebrandt M. Open, aware, and active: contextual approaches as an emerging trend in the behavioral and cognitive therapies. Annu Rev Clin Psychol. 2011;7:141-68.

21. Teasdale JD, Segal Z, Williams JMG. How does cognitive therapy prevent depressive relapse and why should attentional control (mindfulness) training help? Behav Res Ther. 1995;33:25-39.

22. Wells A. Emotional disorders and metacognition: Innovative cognitive therapy. Chichester: John Wiley \& Sons; 2002.

23. Hayes SC, Strosahl KD, Wilson KG. Acceptance and Commitment Therapy: An Experiential Approach to Behavior Change. New York: Guilford Press; 1999.

24. Linehan MM. Dialectical behavioral therapy: a cognitive behavioral approach to parasuicide. J Pers Disord. 1987;1:328-33.

25. Tsai M, Kohlenberg RJ, Kanter JW, Kohlenberg B, Follette WC, Callaghan GM A guide to functional analytic psychotherapy: awareness, courage, love and behaviorism. New York: Springer; 2008.

26. Jacobson NS, Margolin G. Marital Therapy: strategies based on social learning and behavior exchange principles. New York: Brunner/Mazel; 1979.

27. Chadwick P. Person-based cognitive therapy for distressing psychosis. Chichester: John Wiley \& Sons; 2006.

28. Khoury B, Lecomte T, Gaudiano BA, Paquin K. Mindfulness interventions for psychosis: a meta-analysis. Schizophr Res. 2013;150:176-84.

29. Liberati A, Altman DG, Tetzlaff J, Mulrow C, Gotzsche PC, loannidis JP, et al The PRISMA statement for reporting systematic reviews and meta-analyses of studies that evaluate health care interventions: explanation and elaboration. PLoS Med. 2009;6:e1000100.

30. Churchill R, Moore THM, Furukawa TA, Caldwell DM, Davies P, Jones H, Shinohana K, Imai H, Lewis G, Hunot V. 'Third wave' cognitive andbehavioural therapies versus treatment as usual for depression. Cochrane Database of Systematic Reviews 2013, Issue 10. Art.No:: CD008705. doi:10.1002/14651858.CD008705.pub2.
31. World Health Organization. International statistical classification of diseases and related health problems, tenth revision. Geneva: World Health Organization; 1992.

32. American Psychiatric Association. Diagnostic and Statistical Manual of Mental. Disorders. 4th ed. Washington, DC: American Psychiatric Association; 1994

33. Cieza A, Geyh S, Chatterji S, Kostanjsek N, Üstün B, Stucki G. ICF linking rules: an update based on lessons learned. J Rehabil Med. 2005;37:212-8.

34. Thomas BH, Ciliska D, Dobbin M, Micucci S. A process for systematically reviewing the literature: providing the research evidence for public health nursing interventions. Worldviews Evid Based Nurs. 2004;1:176-84.

35. Penn DL, Meyer PS, Evans E, Wirth RJ, Cai K, Burchinal M. A randomized controlled trial of group cognitive-behavioral therapy vs. enhanced supportive therapy for auditory hallucinations. Schizophr Res. 2009;109:52-9.

36. Fowler D, Hodgekins J, Painter M, Reilly T, Crane C, Macmillan I. Cognitive behaviour therapy for improving social recovery in psychosis: a report from the ISREP MRC Trial Platform study (Improving Social Recovery in Early Psychosis). Psychol Med. 2009;39:1627-36.

37. Penn DL, Uzenoff SR, Perkins D, Mueser KT, Hamer R, Waldheter E. A pilot investigation of the Graduated Recovery Intervention Program (GRIP) for first episode psychosis. Schizophr Res. 2011:125:247-56.

38. Waller H, Emsley R, Freeman D, Bebbington P, Dunn G, Fowler D, et al. Thinking Well: a randomised controlled feasibility study of a new CBT therapy targeting reasoning biases in people with distressing persecutory delusional beliefs. J Behav Ther Exp Psychiatry. 2015:48:82-9.

39. Dannahy L, Hayward M, Strauss C, Turton W, Harding E, Chadwick P. Group person-based cognitive therapy for distressing voices: pilot data from nine groups. J Behav Ther Exp Psychiatry. 2011;42:111-6.

40. Shawyer F, Farhall J, Mackinnon A, Trauer T, Sims E, Ratcliff K, et al. A randomised controlled trial of acceptance-based cognitive behavioural therapy for command hallucinations in psychotic disorders. Behav Res Ther. 2012;50:110-12.

41. Grant PM, Huh GA, Perivoliotis D, Stolar NM, Beck AT. Randomized trial to evaluate the efficacy of cognitive therapy for low-functioning patients with schizophrenia. Arch Gen Psychiatry. 2012:69:121-7.

42. Johns LC, Oliver JE, Khondoker M, Byrne M, Jolley S, Wykes T, et al. The feasibility and acceptability of a brief Acceptance and Commitment Therapy (ACT) group intervention for people with psychosis: the 'ACT for life' study. J Behav Ther Exp Psychiatry. 2016;50:257-63.

43. Williams E, Ferrito M, Tapp J. Cognitive-behavioural therapy for schizophrenia in a forensic mental health setting. J Forensic Pract. 2014;16:68-77.

44. Laithwaite H, O'Hanlon M, Collins P, Doyle P, Abraham L, Porter S, et al. Recovery after psychosis (RAP): a compassion focused programme for individuals residing in high security settings. Behav Cogn Psychother. 2009:37:511-26.

45. Farhall J, Freeman NC, Shawyer F, Trauer T. An effectiveness trial of cognitive behaviour therapy in a representative sample of outpatients with psychosis. $\mathrm{Br}$ J Clin Psychol. 2009;48:47-62.

46. Birchwood M, Trower $\mathrm{P}$. The future of cognitive-behavioural therapy for psychosis: not a quasi-neuroleptic. Br J Psychiatry. 2006;188:107-8.

47. Mulholland C, Cooper S. The symptom of depression in schizophrenia and its management. Adv Psychiatr Treat. 2006;6:169-77.

48. Morris EM, Johns LC, Oliver JE. Acceptance and commitment therapy and mindfulness for psychosis. Hoboken, NJ: John Wiley \& Sons; 2013.

49. Hartley S, McArthur M, Coenen M, Cabello M, Covelli V, Roszczynska-Michta J, et al. Narratives reflecting the lived experiences of people with brain disorders: common psychosocial difficulties and determinants. PLoS One. 2014:9(5):e96890.

50. Davidson L, Tondora J, Lawless MS, O'Connell M, Rowe M. A practical guide to recovery-oriented tools for transforming mental health care. New York: Oxford University Press; 2009

51. Slade M. Personal Recovery and mental illness. A guide for mental health professionals. New York: Cambridge University Press; 2009.

52. Slade $M$, Amering $M$, Farkas $M$, Hamilton $B$, O'Hagan M, Panther $G$, et al. Uses and abuses of recovery: implementing recovery-oriented practices in mental health systems. World Psychiatry. 2014;13:12-20.

53. Lysaker PH, Dimaggio G. Metacognitive capacities for reflection in schizophrenia: implications for developing treatments. Schizophr Bull. 2014:40:487-91.

54. Bargenquast R, Schweitzer RD. Enhancing sense of recovery and self-reflectivity in people with schizophrenia: a pilot study of metacognitive narrative psychotherapy. Psychol Psychother. 2014;87:338-56. 